\title{
$\mathrm{ABS} /$ 실리케이트 복합체의 제조 및 열적특성 연구
}

\author{
윤이슬 · 김연철 \\ 공주대학교 고분자공학전공 \\ 330-717 충남 천안시 부대동 275 \\ (2010년 12월 29일 접수, 2011년 1월 17일 채택)
}

\section{Study on Fabrication and Thermal Properties of the ABS/silicate Composites}

\author{
Lee Seol Youn and Youn Cheol Kim ${ }^{\dagger}$
}

\begin{abstract}
Major in Polymer Science \& Engineering, Kongju National University, 275 Budae-dong, Cheonan-si, Chungnam 330-717, Korea
\end{abstract}
(Received 29 December 2010; accepted 17 January 2011)

\begin{abstract}
요 약
$\mathrm{ABS} /$ 실리케이트 복합체를 clay의 종류 및 함량을 변화시키며 에멀젼 중합을 이용하여 제조하였다. ABS의 화학구조 는 적외선분광기(FT-IR)를 이용하여 이중결합 C-H 신축진동 피크 $\left(3000 \mathrm{~cm}^{-1}\right.$ 근처 $)$ 의 변화를 통해 확인하였다. $\mathrm{ABS} /$ 실 리케이트 복합체의 열적특성은 시차주사열용량분석기(DSC) 와 열중량분석기(TGA)를 이용하여 관찰하였다. Clay의 종 류에 따른 $\mathrm{ABS}$ 의 유리전이온도에는 큰 변화가 나타나지 않음을 알 수 있었다. TGA에 의한 분해온도는 $20 \mathrm{~A}$ 의 함량 이 $3 \mathrm{wt} \%$ 인 $\mathrm{ABS} / 20 \mathrm{~A}$ 복합체에서 가장 높은 값을 나타내었다. 복합체의 실리케이트 분산정도는 X-선회절(XRD)법을 이용하여 측정하였다. $\mathrm{ABS} / 20 \mathrm{~A}$ 복합체의 실리케이트 분산은 $20 \mathrm{~A}$ 함량에 의존하였고, 함량이 $5 \mathrm{wt} \%$ 이상 첨가되었 을 때 $20 \mathrm{~A}$ 의 회절 피크가 나타나는 것을 확인하였다.
\end{abstract}

\begin{abstract}
ABS/silicate composites with different clay types and compositions were prepared by in situ emulsion polymerization. The chemical structure of ABS was confirmed by the change of C-H stretching peak (near $\left.3000 \mathrm{~cm}^{-1}\right)$ in fourier transform-infrared(FT-IR) spectrum. The thermal properties of the ABS/silicate composites were investigated by differential scanning calorimetry(DSC) and thermogravimetric analyzer(TGA). There was no distinct change in glass transition temperature of the $\mathrm{ABS} /$ silicate composites with different clay types. TGA curve indicates a dramatic increase in degradation temperature in case of $\mathrm{ABS} / 20 \mathrm{~A}$ composite with $3 \mathrm{wt} \% 20 \mathrm{~A}$. The silicate dispersion in the composites was measured by X-ray diffraction(XRD). The silicate dispersion in ABS/20A composites depended on the 20A composition. XRD results showed that the diffraction peak of the ABS/20A composite appeared when the content of $20 \mathrm{~A}$ was higher than $5 \mathrm{wt} \%$.
\end{abstract}

Key words: ABS/silicate Composite, Emulsion, Silicate Dispersion, Thermal Properties

\section{1. 서 론}

고분자 나노복합재료(nanocomposite)는 유기매트릭스인 고분자 와 나노크기의 무기충전제와의 복합체를 의미하며 무기충전제를 나 노 크기로 분산된 물질을 말하는데, 이러한 분산특성으로 인해 기 존의 마이크로 단위의 분산상을 가진 복합체와 매우 다른 독특한 물 성을 보이고 있으며, 주로 유기·무기 혼성복합체에 대한 연구가 그 주류를 이루고 있다[1-9]. 이러한 특성으로 자동차, 항공우주 및 선 박, 포장재 및 용기, 도료 및 코팅, 전자정보, 건축토목, 의료 등 사 회전반에 걸쳐 응용이 되고 있다. 이들 중 층상 실리케이트(layered silicate)를 이용한 고분자 나노복합재료는 clay의 실리케이트층 사

\footnotetext{
${ }^{\dagger}$ To whom correspondence should be addressed.

E-mail: younkim@kongju.ac.kr

*이 논문은 KAIST 임선기 교수님의 정년을 기념하여 투고되었습니다.
}

이에 고분자를 삽입하는 삽입형(intercalated) 나노복합재료와 실리 케이트 층을 완전히 분산시키는 박리형(exfoliated) 나노복합재료 2 가지 종류가 있다. 층상구조를 갖는 무기 나노 입자를 이용하여 고 분자 복합재료를 제조하는 방법으로는 용융혼합법(melt intercalation), 용제혼합법(solvent intercalation), 중합혼합법(in situ polymerization) 등이 있다. 층상 실리케이트는 결정상에서의 수소결합과 음전하로 강한 결합력을 가지고 있어 분산이 어려워 양이온 치환이나 유기물 개질 등의 방법을 이용하고 있다.

아크릴로니트릴-스티렌-부타디엔 공중합체(acrylonitrile-styrenebutadiene, $\mathrm{ABS}$ )는 아크릴로니트릴의 내화학성과 열안정성, 부타디 엔에 의한 toughness와 충격강도, 스티렌에 의한 강직도와 가공특 성 등을 조절할 수 있기 때문에 다양한 분야에 널리 이용되고 있는 고분자재료로서 경제성과 우수한 물성으로 인해 많은 연구가 진행 되고 있다[10-12]. ABS 수지의 전기·전자제품으로의 사용 확대를 
위해서는 난연특성 향상과 함께 열적특성의 개선이 필요하다. $\mathrm{ABS}$ 수지의 경우 $85 \sim 95^{\circ} \mathrm{C}$ 의 열변형 온도를 가지고 있으며, $260{ }^{\circ} \mathrm{C}$ 이 상에선 열분해가 급속하게 진행되어 충격강도 등 물성이 대폭 감소 하는 특성을 가지고 있다. 이와 같은 문제점을 개선할 수 있는 방안 중의 하나가 $\mathrm{ABS} /$ 실리케이트 나노복합체이다.

공업적인 중요성에도 불구하고 $\mathrm{ABS} /$ 실리케이트 복합체에 대한 연구[13-20]는 미미한 실정으로 Jang[13,14] 등은 에멀젼 중합을 통해 ABS/sodium montmorillonite 나노복합체에 대한 연구를 수행하였고, Modesti[15,16] 등은 용액법을 이용하여 ABS/clay 나노복합체에 대한 연구를 수행하였다. 또한 $\operatorname{Kim}[16,17]$ 등은 $\mathrm{ABS} /$ 실리케이트 복합체에 서 실리케이트 분산성에 미치는 반응형 양친성 물질(reactive amphiphiles)의 영향을 고찰하였다. 여기서 양친성 물질이란 친수성과 소 수성 부분으로 이루어지는 유기화합물로 실리케이트와의 상호작용을 증가시켜 실리케이트의 분산성에 영향을 주는 것으로 알려져 있다. 이들 소수의 연구들은 실리케이트를 무기분산상 소재로 선택하여 합 성된 나노복합체에서 나타나는 영향을 분석하는데 국한되고 있다.

따라서 본 연구에서는 에멀젼 중합을 이용하여 clay의 종류와 함 량을 달리하여 $\mathrm{ABS}$ /실리케이트 복합체를 제조하고, 분해온도와 유 리전이온도 등 열적특성을 분석하고, 각각의 $\mathrm{ABS} /$ 실리케이트 복합 체의 실리케이트 분산정도를 X-선 회절법을 통해 확인하며, 실리케 이트 분산성과 열적특성과의 상관관계를 규명하고자 한다.

\section{2. 실 험}

\section{2-1. 실험재료}

실험에는 Southern Clay Products의 Laponate와 Closite-Na, Closite $20 \mathrm{~A}$ (abbreviation: $20 \mathrm{~A}$ ) 등 3종의 실리케이트가 사용되었다. $20 \mathrm{~A}$ 는 dimethyl dihydrogenate tallow ammonium ions을 가지고 이온 교 환되었고, Tallow는 대략 $\mathrm{C}_{18} 65 \%, \mathrm{C}_{16} 30 \%$ 그리고 $\mathrm{C}_{14} 5 \%$ 의 화학 조성을 가진다. Laponate와 Closite- $\mathrm{Na}$ 는 각각 $73 \mathrm{meq} / 100 \mathrm{~g}$ 과 92.6 $\mathrm{meq} / 100 \mathrm{~g}$ 의 양이온교환능(cation exchange capacity, CEC)을 가진 다. Closite-Na의 입경은 $150 \mathrm{~nm}$ 이고, Laponate는 synthetic smectite silicate로 20-30 nm의 종횡비(aspect ratio)를 가진다. 아크릴로니트 릴(acrylonitrile, AN), 스티렌(styrene, St), 계면활성제인 dodecylbenzenesulfonic acid sodium salt(DBS-Na), 그리고 개시제인 cumene hydroperoxide는 Aldrich에서 구입하여 정제 없이 사용하 였다. Polybutadiene(PBD) (52 wt\% in water, average particle size is $250 \mathrm{~nm})$ 는 제일모직 제품을 사용하였다.

\section{2-2. 실험방법}

2-2-1. ABS/clay 복합체의 제조

기계적 교반기가 부착된 $500 \mathrm{ml} \mathrm{5구} \mathrm{플라스크에} \operatorname{PBL}(40 \mathrm{~g})+$ water(236.92 g), acrylonitrile(15 g)+cumene hydroperoxide( $0.20 \mathrm{~g})$, DBS-Na(2.5 g)+water(22.5 g), dextrose( $0.3 \mathrm{~g})+$ Water(0.556 g), clays + poly(vinylpyrrolidone) $(1 \mathrm{~g})+$ water(200 g)을 차례로 주입하여 상온 에서 30 분 동안 $200 \mathrm{rpm}$ 으로 교반시킨 후 물중탕을 이용하여 $60{ }^{\circ} \mathrm{C}$ 에서 30 분 동안 유지하고, sodium pyrophosphat $(0.2 \mathrm{~g})+$ ferrous sulfate $(0.02 \mathrm{~g})+$ water $(4.18 \mathrm{~g})$ 을 추가 주입하여 $70{ }^{\circ} \mathrm{C}$ 에서 10 분간 교반하였다. Styrene( $30 \mathrm{~g})+$ acrylonitrile( $15 \mathrm{~g})+$ cumene hydroperoxide $(0.4 \mathrm{~g})$ 을 주사 기에 넣고 syringe pump를 이용하여 2시간 30 분 동안 $0.244 \mathrm{cc} / \mathrm{min}$ 의 일정한 속도로 주입하였다. 마지막 단계로 $75^{\circ} \mathrm{C}$ 에서 1 시간동안 종결반응시키고 $50{ }^{\circ} \mathrm{C}$ 에서 2 일 동안 진공 건조하였다. Table 1 에 사 용된 조성을 나타내었다.

\section{2-2-2. 측정}

화학구조 분석을 위한 적외선분광기(FT-IR)는 Bomen-MB-100 을 이용하여 $400 \sim 4,000 \mathrm{~cm}^{-1}$, 파수 범위에서 스캔수는 16으로 실험 을 수행하였다. 시차주사열용량분석기(DSC)와 열중량분석기 (TGA)의 측정은 TA Instruments DSC 10 을 이용하였으며, 승온속 도는 $20^{\circ} \mathrm{C} / \mathrm{min}$ 로 고정하였다. 모든 열분석은 질소분위기하에서 수 행하였다. 복합체의 실리케이트 분산정도 변화를 확인하기 위한 X선 회절분석기(XRD)와 투과전자현미경(TEM)을 이용하였다. XRD는 Rigaku사의 X-ray Diffractometer $(\mathrm{Cu} \mathrm{K} \alpha$ radiation with $\lambda=0.15406$ $\mathrm{nm}$ )를 이용하였다. 승각속도는 $5 \% \mathrm{~min}$ 으로 고정하였다. 상온, 40 $\mathrm{kV}, 40 \mathrm{~mA}$ 의 조건을 이용하였다.

\section{3. 결과 및 고찰}

$\mathrm{ABS}$ 의 제조 여부는 FT-IR 분석을 통해 확인하였고, IR 스펙트럼 을 Fig. 1에 나타내었다. 우선 제조된 ABS의 $1,600 \mathrm{~cm}^{-1}-1,400 \mathrm{~cm}^{-1}$

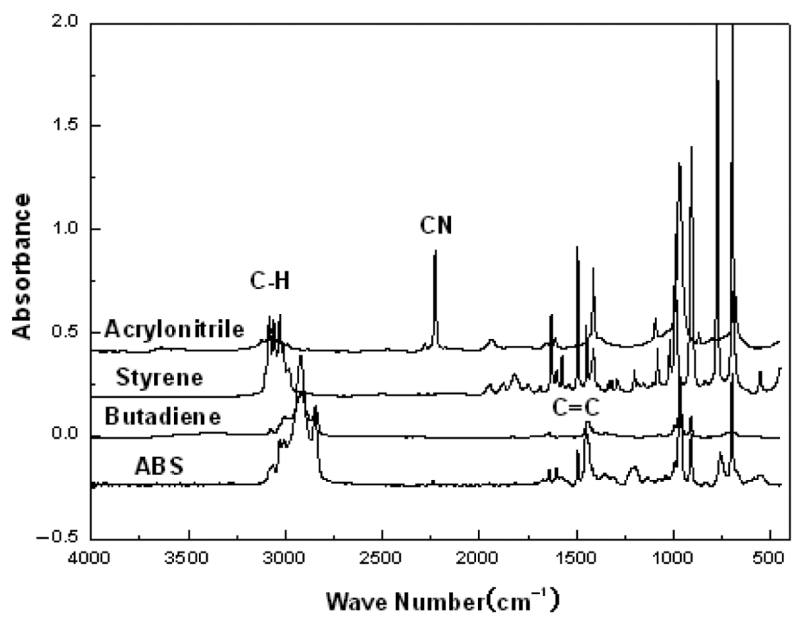

Fig. 1. FT-IR spectra of the synthesized ABS and monomers.

Table 1. The compositions of the ABS/silicate composites

\begin{tabular}{cccccc}
\hline \hline Sample & Acrylonitrile & Styrene & Butadiene & Silicate(phr $\left.{ }^{*}\right)$ & Others(phr) \\
\hline ABS & 40 & 30 & 30 & 0 & Closite Na 3 \\
ABS-Na & 40 & 30 & 30 & Laponate 3 & DBS-Na : 2.5 \\
ABS-Lapo & 40 & 30 & 30 & 20 A 1 & Initiator : 0.4 \\
ABS-1 & 40 & 30 & 30 & 20 A 3 & 20 A 5 \\
ABS-3 & 40 & 30 & 30 & 20 A 7 & \\
ABS-5 & 40 & 30 & 30 & 30 & \\
ABS-7 & 40 & 30 & & & \\
\hline
\end{tabular}

*phr: parts per hundred resin.

Korean Chem. Eng. Res., Vol. 49, No. 3, June, 2011 
의 peak는 방향족 이중결합 $(\mathrm{C}=\mathrm{C})$ 의 신축진동에 의한 것으로 확인 할 수 있다. 비닐계 단량체(아크릴로니트릴, 스티렌, 부타디엔)의 중 합이 진행되어 이중결합이 깨져 단일결합 비중이 증가함에 따라 $3,000 \mathrm{~cm}^{-1}$ 근처에서 나타나는 C-H 신축진동 피이크가 오른쪽으로 피크가 이동함을 관찰할 수 있다. 즉 $2,900 \mathrm{~cm}^{-1}$ 근처에선 $\mathrm{sp} 3 \mathrm{C}-\mathrm{H}$ 신축진동이 나타나고, $3,000 ~ 3,020 \mathrm{~cm}^{-1}$ 에선 $\mathrm{sp} 2$ 신축진동이 나타 나는데, $\mathrm{ABS}$ 의 경우 스티렌 단량체와 비교했을 때 낮은 파수 영역 으로 상당히 이동하였음을 알 수 있고, 이는 중합의 진행을 나타내 는 것으로 해석할 수 있다.

Closite Na, 20A, Laponite 등 3가지 종류의 clay에 대해서 함량을 $3 \mathrm{wt} \%$ 로 고정한 다음 $\mathrm{ABS}$ 를 제조하고 분해거동과 유리전이온도 변화를 TGA와 $\mathrm{DSC}$ 를 이용하여 분석하였다. Fig. 2 는 TGA 분석 결과를 나타낸 것이다. Clay로 $20 \mathrm{~A}$ 를 사용한 $\mathrm{ABS} /$ 실리케이트 복 합체의 경우 분해온도(degradation temperature, $\mathrm{T}_{d}$ )와 감량거동 등 에 있어서 열적 특성이 가장 우수함을 알 수 있다. Fig. 3은 clay의 종류에 따른 $\mathrm{ABS}$ /실리케이트 복합체의 $\mathrm{DSC}$ 측정결과를 나타낸 것 이다. 폴리스티렌의 유리전이온도(glass transition temperature, $\mathrm{T}_{g}$ ) 가 $100^{\circ} \mathrm{C}$ 정도로, 제조한 $\mathrm{ABS}$ 의 $\mathrm{T}_{g}$ 도 $100^{\circ} \mathrm{C}$ 부근에서 관찰할 수 있다. 사용된 clay중 $20 \mathrm{~A}$ 가 가장 높은 $\mathrm{T}_{g}$ 를 나타내었고, 이는 열적 특성을 고려할 때 $20 \mathrm{~A}$ 가 가장 효율적임을 보여주는 것이다. 이와 같은 열적 특성 변화와 clay의 분산성과의 상관관계를 살펴보기 위

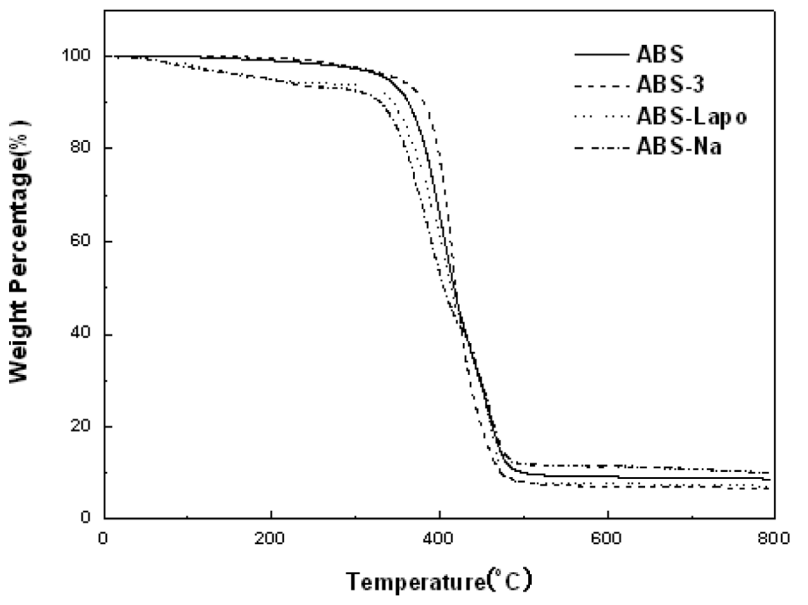

Fig. 2. TGA curves of ABS/silicate composites with different clay type.

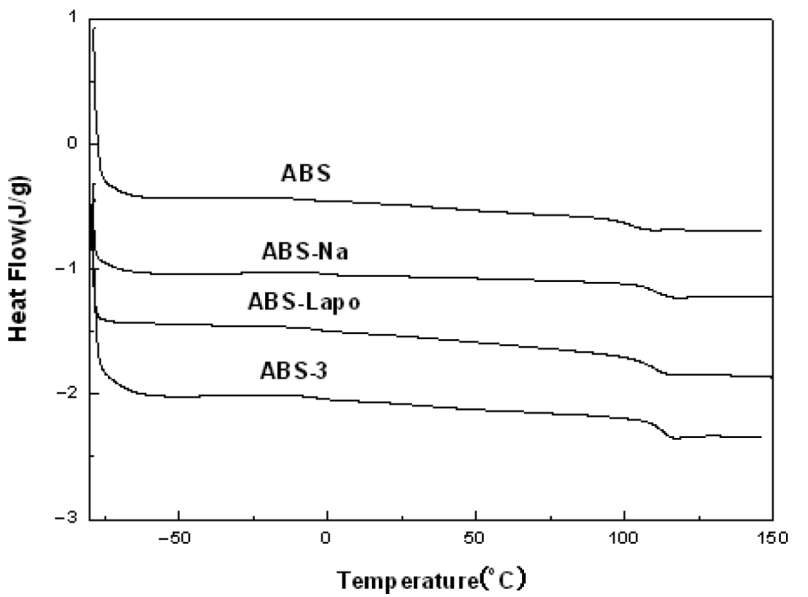

Fig. 3. DSC thermograms of ABS/silicate composites with different clay type.

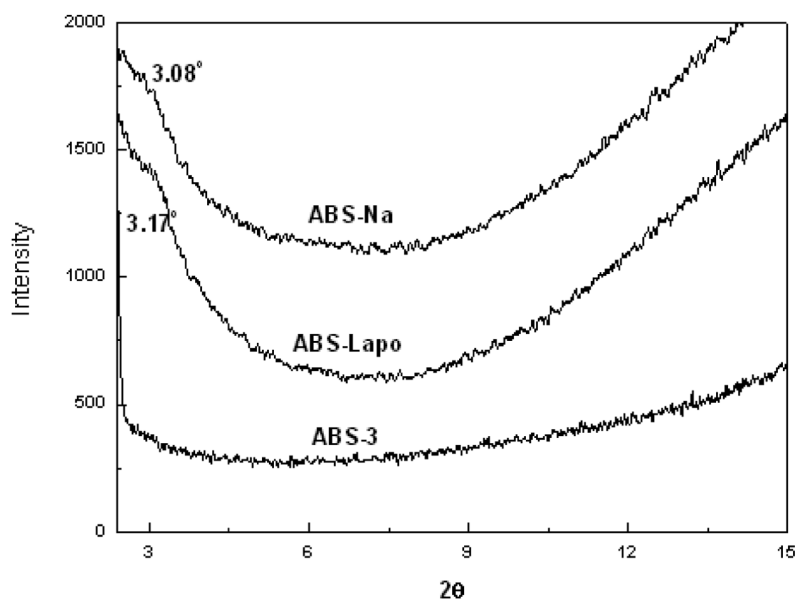

Fig. 4. XRD patterns of ABS/silicate composites with different clay type.

해 X-선 회절(XRD) 실험을 수행하였다.

Fig. 4는 clay 종류에 따른 $\mathrm{ABS} /$ 실리케이트 복합체의 XRD 결과 를 나타낸 것이다. Laponite와 Closite $\mathrm{Na}$ 의 경우 낮은 회절각에서 피이크가 나타나고 있음을 볼 수 있다. 반면 $20 \mathrm{~A}$ 의 경우는 회절 피 이크가 나타나지 않았는데, 이는 $\mathrm{ABS}$ 중합시 실리케이트의 층간 분 리가 이루워져 우수한 분산성을 보였기 때문으로 해석할 수 있고, 이 와 같은 결과는 $20 \mathrm{~A}$ 의 경우 유기물로 치환되어 $\mathrm{ABS}$ 내에서의 층 간 분리가 다른 실리케이트들보다 효율적이기 때문으로 판단된다. 고분자/실리케이트 복합체에서 실리케이트의 분산 정도를 평가하기 위해 XRD 결과에서 실리케이트의 $\mathrm{d}_{001}$-spacing으로 알려져 있는 $2.29 \mathrm{~nm}(20 \mathrm{~A})$ 의 피이크 위치나 강도를 주로 활용한다. $\mathrm{d}_{001}$-spacing (이하 d-spacing으로 표시)은 001 plane 격자간격을 나타내는 것으로 $2 \mathrm{~d}_{001} \sin \theta=$ 의 Bragg 법칙을 이용하여 계산한 값으로 Closite $\mathrm{Na}$ 는 $2.86 \mathrm{~nm}$, Laponite는 $2.78 \mathrm{~nm}$ 를 나타내었다. 여기서 $20 \mathrm{~A}$ 가 다른 clay와 비교하여 분산성이 우수한 이유는 유기물로 치환되어 $\mathrm{ABS}$ 와의 혼화성이 양호하기 때문으로 판단된다.

$\mathrm{ABS} /$ 실리케이트 복합체중 열적특성이 상대적으로 우수한 20A에 대해 추가 실험을 진행하기 위해 $20 \mathrm{~A}$ 의 함량을 $1 \mathrm{wt} \%, 3 \mathrm{wt} \%, 5$ $\mathrm{wt} \%, 7 \mathrm{wt} \%$ 로 변화시켜 $\mathrm{ABS} /$ 실리케이트 복합체를 제조한 후 열적 특성과 실리케이트 분산성을 평가하였다.

Fig. 5 는 $20 \mathrm{~A}$ 의 함량이 다른 $\mathrm{ABS} / 20 \mathrm{~A}$ 복합체의 분해거동을 측 정한 결과를 나타낸 것이다. $20 \mathrm{~A}$ 의 함량이 $3 \mathrm{wt} \%$ 인 $\mathrm{ABS} / 20 \mathrm{~A}$ 복 합체의 $\mathrm{T}_{d}$ 가 다른 함량의 복합체보다 높게 나타남을 확인할 수 있 다. 이는 앞에서도 언급하였듯이 실리케이트의 분산성과 연관이 있

Table 2. The summary for thermal properties and d-spacing of the ABS/silicate composites

\begin{tabular}{cccc}
\hline \hline Sample & $\mathrm{T}_{g}\left({ }^{\circ} \mathrm{C}\right)$ & $\mathrm{T}_{d}{ }^{*}\left({ }^{\circ} \mathrm{C}\right)$ & $\mathrm{d}$-spacing(nm) \\
\hline ABS & 104 & 363 & - \\
ABS-Na & 114 & 329 & 2.86 \\
ABS-Lapo & 113 & 345 & 2.78 \\
ABS-1 & 112 & 355 & - \\
ABS-3 & 114 & 381 & - \\
ABS-5 & 112 & 333 & 1.89 \\
ABS-7 & 112 & 367 & 1.95 \\
\hline
\end{tabular}

*The temperature at $10 \mathrm{wt} \%$ weight loss 


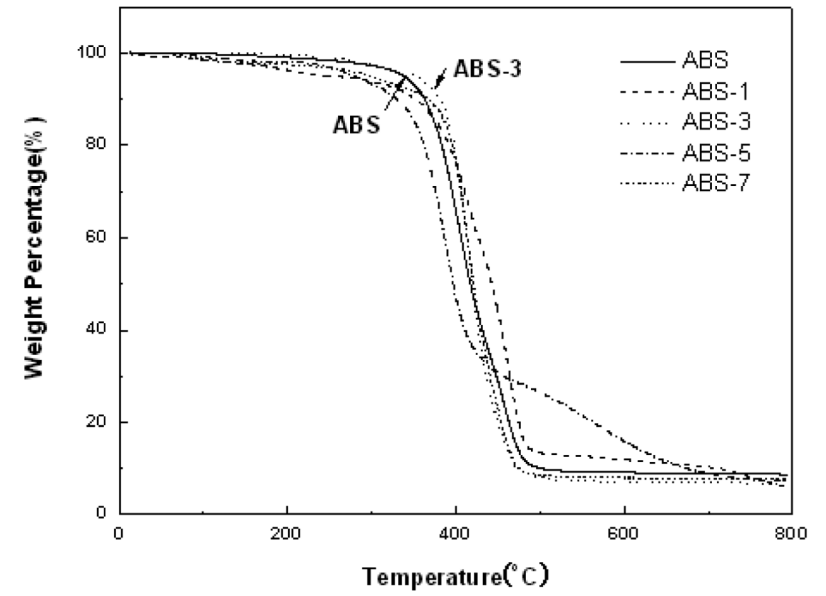

Fig. 5. TGA curves of $\mathrm{ABS} / 20 \mathrm{~A}$ composites with different $20 \mathrm{~A}$ content.

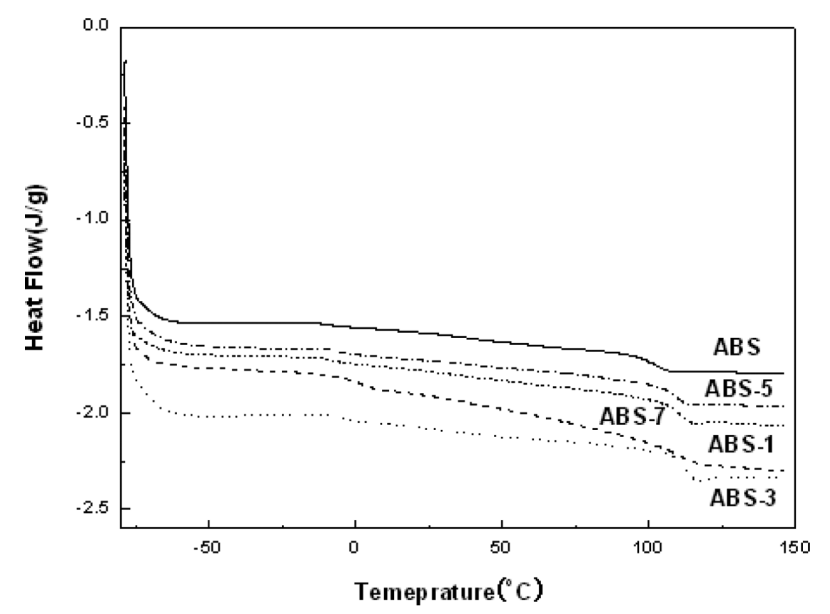

Fig. 6. DSC thermograms of $\mathrm{ABS} / 20 \mathrm{~A}$ composites with different $20 \mathrm{~A}$ content.

을 것으로 판단되고, 유기화된 실리케이트 층간거리가 확대되면서 고분자 내에 분산성이 증가했기 때문이다.

Fig. 6 은 $20 \mathrm{~A}$ 의 함량이 다른 $\mathrm{ABS} / 20 \mathrm{~A}$ 복합체의 $\mathrm{DSC}$ 결과를 보 여주는 것이다. $\mathrm{ABS}$ 보다는 $\mathrm{ABS} / 20 \mathrm{~A}$ 복합체의 유리전이온도가 높 게 나타남을 볼 수 있고, $20 \mathrm{~A}$ 가 $3 \mathrm{wt} \%$ 함유된 $\mathrm{ABS} / 20 \mathrm{~A}$ 복합체의 $\mathrm{T}_{g}$ 가 $114{ }^{\circ} \mathrm{C}$ 정도로 가장 높음을 알 수 있다. 실리케이트를 첨가한 $\mathrm{ABS} / 20 \mathrm{~A}$ 복합체의 $\mathrm{T}_{g}$ 가 대략 $8{ }^{\circ} \mathrm{C}$ 정도 높게 나타나는데, 이는 첨 가된 실리케이트가 $\mathrm{ABS}$ 의 사슬 유동성을 억제하기 때문으로 판단 된다. $20 \mathrm{~A}$ 를 $3 \mathrm{wt} \%$ 함유하는 $\mathrm{ABS} / 20 \mathrm{~A}$ 복합체의 유리전이온도가 가장 높게 나타나는 이유 또한 실리케이트 분산성이 $3 \mathrm{wt} \%$ 복합체 에서 가장 우수하기 때문으로 판단된다.

고분자/실리케이트 복합체는 고분자 수지 안에 clay가 분산되는 양상에 따라서 크게 삽입형(intercalated)과 박리형(exfoliated)으 로 나누어진다. 삽입형은 고분자가 clay층 내로 삽입되어 고분자 사슬이 확장되면서 정열이 되는 적층 구조이고, 이와 같이 층간간 격이 고분자가 삽입되어 증가하는 경우, $\mathrm{XRD}$ 패턴은 저각(low angle) 위치로 이동하게 된다. 박리형은 clay가 고분자 수지 내에 서 나노 크기로 균일하게 분산되어 실리케이트 판상 구조를 유지 하지 못하고 박리되며 XRD로 분석하면 diffraction 피크가 사라 지는 것이 관찰된다. 또한 피이크 폭이 넓은 것은 층간 간격이 넓

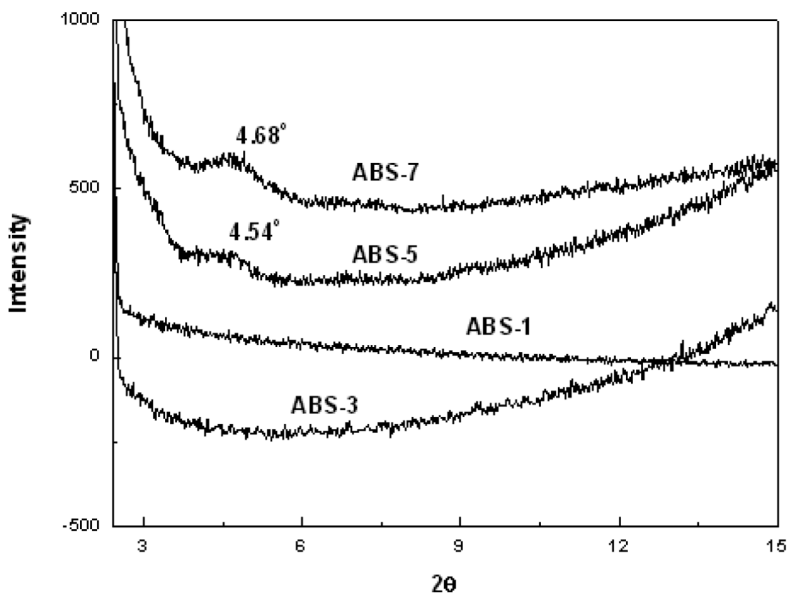

Fig. 7. XRD patterns of ABS/20A composites with different $20 \mathrm{~A}$ content.

이가 다양하게 존재하거나 결정면이 굴곡져 있는 것으로 설명할 수 있다.

Fig. 7에 20A 함량에 따른 $\mathrm{ABS} / 20 \mathrm{~A}$ 복합체의 XRD pattern을 나 타내었다. $20 \mathrm{~A}$ 의 함량이 $3 \mathrm{wt} \%$ 까지는 $\mathrm{ABS} / 20 \mathrm{~A}$ 복합체의 $\mathrm{XRD}$ 회절 피이크가 관찰되지 않은 반면, $5 \mathrm{wt} \%, 7 \mathrm{wt} \% \mathrm{ABS} / 20 \mathrm{~A}$ 복합 체의 경우 20 가 4.68 과 $4.54^{\circ}$ 에서 $20 \mathrm{~A}$ 의 회절 피이크가 관찰되었고, $\mathrm{d}$-spacing은 각각 1.89 와 $1.95 \mathrm{~nm}$ 를 나타내었다. $20 \mathrm{~A}$ 가 $1 \mathrm{wt} \%, 3$ $\mathrm{wt} \%$ 포함된 $\mathrm{ABS} / 20 \mathrm{~A}$ 복합체의 경우는 실리케이트가 층간 중합에 효과적으로 분산된 반면, $20 \mathrm{~A}$ 가 $5 \mathrm{wt} \%$ 이상 첨가된 $\mathrm{ABS} / 20 \mathrm{~A}$ 복 합체의 경우는 $\mathrm{ABS}$ 중합 조건내에서 층간 분산이 일어나지 못하고, 삽입형의 복합체를 형성했기 때문으로 판단된다.

\section{4. 결 론}

개시제로 cumene hydroperoxide를 이용한 에멀젼중합으로 ABS/ 실리케이트 복합체를 clay의 종류 및 함량을 변화시키며 제조하였 고, 적외선분광기(FT-IR)를 이용하여 C-H 신축진동 피이크가 낮은 파수 영역으로 이동하는 사실로부터 합성여부를 확인하였다. ABS 에 silicate가 첨가됨에 따라 유리전이온도가 증가하였으나, clay의 종류 변화에 대해서는 유리전이온도에 큰 변화가 나타나지 않았 다. $\mathrm{ABS} /$ 실리케이트 복합체의 분해거동은 $\mathrm{ABS} / 20 \mathrm{~A}$ 의 경우 가장 우수한 결과를 나타내었고, $10 \%$ 질량감량이 일어나는 분해온도의 경우 $20 \mathrm{~A}$ 의 함량이 $3 \mathrm{wt} \%$ 에서 가장 높은 값을 보여주었다. 이는 $20 \mathrm{~A}$ 의 분산과 관련된 것으로 판단되고, XRD 실험을 통해 $3 \mathrm{wt} \%$ 까지는 회절 피이크가 나타나지 않지만 $5 \mathrm{wt} \%$ 와 $7 \mathrm{wt} \%$ 에서는 4.68 과 $4.54^{\circ}$ 에서 회절 피이크가 나타남을 확인하였다. 이들 결과 는 $20 \mathrm{~A}$ 를 $3 \mathrm{wt} \%$ 함유하는 $\mathrm{ABS} / 20 \mathrm{~A}$ 복합체의 분산성이 양호하 나 $20 \mathrm{~A}$ 함량이 $5 \mathrm{wt} \%$ 이상이 되면 주어진 중합 조건 내에서 실리 케이트의 분산성이 완전하지 못함을 나타내는 것으로 해석할 수 있다.

\section{감 사}

본 연구는 지식경제부 지정 공주대학교 자동차의장 및 편의부품 지역혁신센터의 지원에 의한 것입니다. 


\section{참고문헌}

1. Nam, P. H., Maiti, P., Okamoto, M., Kotaka, T., Hasegawa, N. and Usuki, A., "A Hierarchical Structure and Properties of Intercalated Polypropylene/clay Nanocomposites,' Polymer, 42, 96339640(2001)

2. Zheng, L., Farris, R. J. and Coughlin, E. B., "Novel Polyofefin Nanocomposites: Synthesis and Characterizations of Metallocenecatalyzed Polyolefin Polyhedral Oligomeric Silsesquioxane Copolymers,' Macromolecules, 34, 8034-8039(2001).

4. Liu, X. and Wu, Q., "PP/clay Nanocomposites Prepared by Grafting-melt Intercalation,' Polymer, 42, 10013-10019(2001).

5. Lele, A., Mackley, M., Galgali, G. and Ramesh, C., "In Situ Rheo$\mathrm{x}$-ray Investigation of Flow-induced Orientation in Layered Silicate-syndiotatic Polypropylene Nanocomposite melt', J. Rheol., 46, 1091-1110(2002)

6. Li, J., Zhou, C. and Gang, W., "Study on Nonisothermal Crystallization of Maleic Anhydride Grafted Polypropylene/montmorillonite Nanocomposite,', Polym. Test., 22, 217-223(2003).

7. Kim, Y. C., "Effect of Maleated Polyethylene on the Crystallization Behavior of LLDPE/clay Nanocomposites', Polym. J., 38, 250-256(2006).

8. Cho, M. S. and Lee, Y. K., "Polymer Nanocomposites Using Nano Clay,' Polymer(Korea), 27, 31 (2006).

9. Choi, Y. S. and Chung, I. J., "Comprehending Polymer-Clay Nanocomposites and Their Future Works", HWAHAK KONGHAK, 46, 23-36(2008).

10. Kulich, D. M., Kelly, P. D. and Pace, J. E., "Encyclopedia of Polymer Science and Engineering,', John Wiley and Sons, NewYork, 1985.

11. Rubin, I. I., "Hand book of Plastic Materials and Technology," Wiley, New York, 1990.

12. Noh, Y. C., Choi, S. O., Lee, J. H. and Nam, G. D., "Nickel Plat- ing Techniques of Blend of ABS-PC Engineering Plastics', HWAHAK KONGHAK, 34, 683-693(1996).

13. Jang, L. J., Kang, C. M. and Lee, D. C., "A New Hybrid Nanocomposite Prepared by Emulsion Copolymerization of ABS in the Presence of Clay,' J. Polym. Sci.: Part B: Polym. Phys., 39, 719-727(2001).

14. Choi, Y. S., Xu, M. and Chung, I. J., "Synthesis of Exfoliated Acrylonitrile-butadiene-styrene Copolymer (ABS) Clay Nanocomposites: Role of Clay as a Colloidal Stabilizer,', Polymer, 46, 531538(2005).

15. Modesti, M., Besco, S., Lorenzetti, A., Causin, V., Marega, C., Gilman, J. W., Fox, D. N., Trulove, P. C., De Long, H. C. and Zammarano, M., "ABS/clay Nanocomposites Obtained by a Solution Technique: Influenece of Clay Organic Modifiers', Macromolecules, 2209-2214(2007).

16. Pourabas, B. and Raeesi, V., "Preparation of ABS/montmorillonite Nanocomposite Using a Solvent/non-solvent Method,' Polymer, 46, 5533-5540(2005).

17. Kim, J. H., Study on Synthesis of Polymer/Layered Silicate Nanocomposites using Reactive Amphiphiles and their Characterization, Ph.D thesis, KAIST, 2007.

18. Kim, J. H., Kim, K., Kim, Y. C. and Chung, I. J., "Effect of Reactive Amphiphiles on the Silicate Dispersion and Degradation Behavior of ABS/layered Silicate Nanocomposites,' Polymer J., 40, 268-273(2008).

19. Wang, S., Hu, Y., Song, L., Wang, Z., Chen, Z. and Fan, W., "Preparation and Thermal Properties of ABS/montmorillonite Nanocomposite,' Polymer Degradation Stability, 77, 423-426(2002).

20. Lim, S.-K., Hong, E.-P., Song, Y.-H., Park, B. J., Choi, H. J. and Chin, I.-J., "Preparation and Interaction Characteristics of Exfoliated ABS/Organoclay Nanocomposite," Polym. Eng. Sci., 50, 504-512(2010). 